\title{
Myopericytoma of the parotid region treated by extracapsular dissection
}

\author{
Anthony Simon Bates, ${ }^{1}$ Paul Craig, ${ }^{2}$ Greg J Knepil ${ }^{3}$
}

'University of Bristol, Bristol, UK

${ }^{2}$ Department of Cellular Pathology, Gloucestershire Hospitals NHS Foundation Trust, Cheltenham, UK ${ }^{3}$ Department of Oral and Maxillofacial Surgery, Gloucestershire Hospitals NHS Foundation Trust, Gloucester, UK

\section{Correspondence to} Anthony Simon Bates, anthony.simon.bates@gmail. com

Accepted 15 March 2014

\section{CrossMark}

To cite: Bates AS, Craig $P_{\text {, }}$ Knepil GJ. BMJ Case Rep Published online: [please include Day Month Year] doi:10.1136/bcr-2013201924

\section{SUMMARY}

Myopericytoma (MPC) is a vascular neoplasm exhibiting differentiation towards perivascular cells. Variable cytoarchitechtural features are visible within MPC, and there is much overlap between MPC, myofibroma and glomus tumours. MPC have a local recurrence rate of $10-20 \%$ and malignancy has been described in a few published cases. Previously, superficial parotidectomy has been recommended for MPC but, in this case, the surgical approach was via extracapsular dissection (ECD). A 66-year-old Caucasian man presented with a palpable mass arising from the superficial lobe of the right parotid gland. Following removal by ECD, the histopathological diagnosis of MPC was made. This is the first published report describing ECD of MPC associated with the parotid gland. ECD is preferable to superficial parotidectomy for small superficial lesions such as MPC, with similar oncological outcomes and fewer functional and aesthetic complications.

\section{BACKGROUND}

This case highlights a rare parotid pathology, details the difficulty of obtaining a preoperative diagnosis of benign parotid neoplasia, the subsequent surgical management options and reconstructive techniques best placed to excise this rare benign parotid tumour.

\section{CASE PRESENTATION}

A 66-year-old Caucasian man was referred by his general medical practitioner to the Department of Maxillofacial Surgery with a painless slow-growing mass on his right cheek, which had been noticeable to the patient for 12 months. The patient had a 20 pack-year history of cigarette use and reported consuming 10-14 units of alcohol per week. There were no obvious relevant infective, inflammatory, autoimmune, traumatic or radiation-induced predisposing factors to parotid pathology. Physical examination of the right parotid region revealed a subcutaneous lump. Ultrasonography of the right parotid gland was then undertaken, which demonstrated a $12 \times 7 \mathrm{~mm}$ well-defined lesion permitting internal echoes.

\section{INVESTIGATIONS}

The patient declined Trucut or fine needle aspiration cytology (FNAc), so excisional biopsy of the lesion was performed by the extracapsular dissection technique (ECD). At the time of surgery, a skin flap was raised over the parotid gland region through a modified facelift incision and the lesion was found to arise from within the superficial

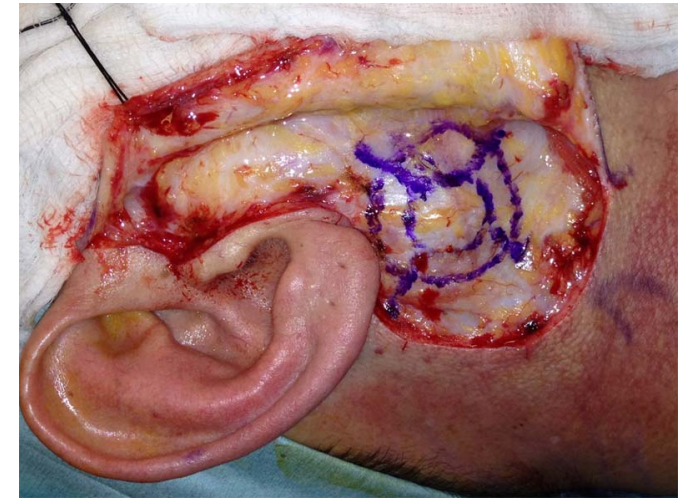

Figure 1 Intraoperative photograph of parotid tumour for illustrative purposes from a similar case. The inner circle is the tumour and the outer circle is the margin. Reproduced with permission.

parotid gland, deep to the parotid fascia (figure 1). Following excision, the lesion appeared rubbery in consistency and grey-tan in colour. The patient was discharged on the same day of surgery without complication.

Histological examination revealed a wellcircumscribed nodule $9 \mathrm{~mm}$ in diameter, within $1 \mathrm{~mm}$ of normal parotid gland parenchyma (figure 2), partly surrounded by adipose and skeletal muscle tissue. It showed typical morphology of myopericytoma, with myoid oval to spindle-shaped cells with a concentric perivascular pattern of growth and expression of smooth muscle actin (figure 3 ) and $\mathrm{h}$ caldesmon in a pericytic pattern. Features of malignant transformation were not apparent. Normal parotid tissue is shown in figure 4.

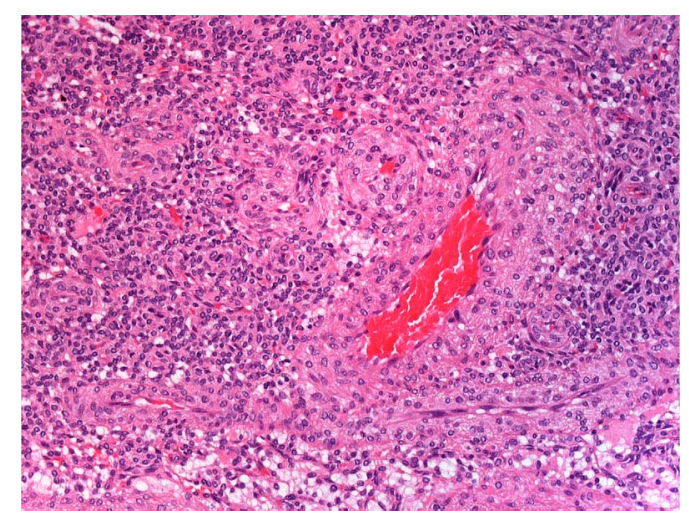

Figure 2 A well circumscribed $9 \mathrm{~mm}$ diameter myopericytoma (on the right) is seen within $1 \mathrm{~mm}$ of the normal parotid gland (on the left). Magnification $\times 20$. 


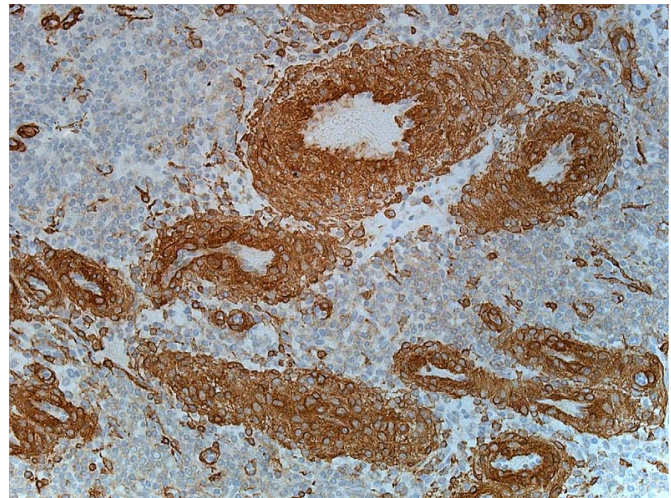

Figure 3 Smooth muscle actin highlights the vascular smooth muscle cells forming the larger vascular structures but not the intervening ovoid pericytic cells. Magnification $\times 150$.

\section{DIFFERENTIAL DIAGNOSIS}

The differential diagnosis of parotid lesions includes common benign parotid neoplasia such as pleomorphic adenoma, which account for $65 \%$ of benign tumours, and adenolymphoma (Warthin's tumour), which form around 25\% of benign histological diagnoses. Rarer adenomas such as basal cell adenoma and oncocytomas are less common (5\%) but could not be excluded before histological analysis. Approximately 10\% of parotid tumours are malignant. ${ }^{1-3}$

\section{TREATMENT}

The right parotid gland was removed by ECD.

\section{OUTCOME AND FOLLOW-UP}

ECD is an oncologically acceptable procedure and provides improved functional and facial aesthetic outcomes for parotid neoplasms compared with superficial parotidectomy. In this case its use allowed definitive biopsy and therapeutic excision of a benign neoplasm of the right parotid salivary gland without recurrence after 18 months of follow-up.

\section{DISCUSSION}

The term 'myopericytoma' was suggested by Requena et al in 1996 and, in 1998, perivascular myoid differentiation was further suggested by Granter et al, ${ }^{2}$ describing myopericytoma as a structurally heterogeneous neoplasm "displaying a histological continuum of perivascular myoid features of

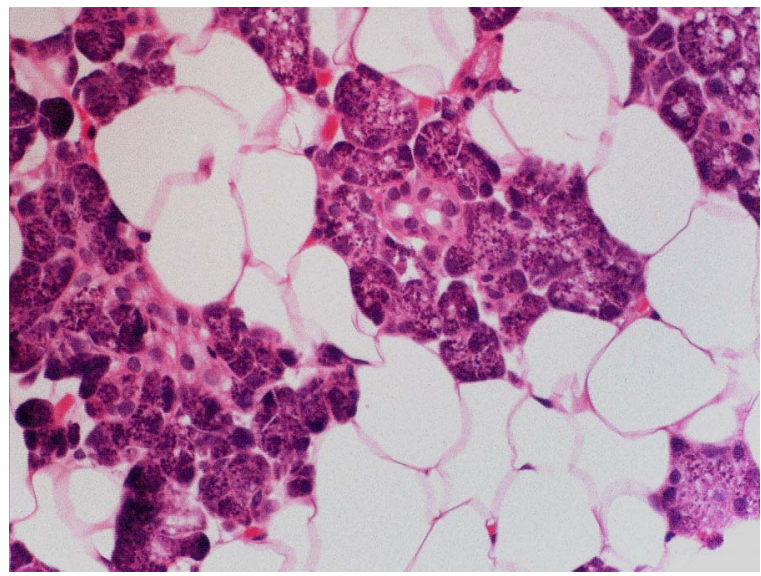

Figure 4 Normal parotid glandular tissue. Magnification $\times 120$. differentiation". In 2002 the World Health Organization officialised the term 'myopericytoma' for use in clinical diagnoses. ${ }^{3}$ Myopericytoma is relatively rare and it is therefore difficult to provide a rapid diagnosis. ${ }^{4} 5$ Recurrence is uncommon, and multifocality has been documented in only two cases. ${ }^{3} 4$ Malignant transformation of myopericytoma is infrequent and directly correlates with lesion depth. ${ }^{1}$

Six percent of head and neck tumours arise from the salivary glands and $80 \%$ of those are thought to arise from the parotid gland. Malignancy is equally distributed between sexes, although women are more likely to be affected by malignant growths over the age of 40 years. ${ }^{6}$ Myopericytoma of the parotid gland should be considered as exceedingly rare. To date, in the English language literature only four published cases of myopericytoma arising from the parotid gland have been reported worldwide. ${ }^{7-10}$

Histologically, numerous cytoarchitechtural features are visible within myopericytoma, with much overlap between myopericytoma, myofibroma and the glomus tumour spectrum. ${ }^{1-3}$ Immunohistochemistry can be helpful in differentiating between these entities and, although glomangiopericytoma and glomangiomyoma may show a similar pattern of immunohistochemical markers, glomus tumours do not exhibit the typical concentric whorled growth pattern of myopericytoma. ${ }^{1-5}$

There are four previous published case reports of myopericytoma of the parotidomasseteric region, all of which were treated by wide clearance with facial nerve preservation or superficial parotidectomy. ${ }^{7-11}$ In our case, ECD of the parotid was conducted to minimise complications associated with superficial parotidectomy such as facial nerve paralysis, facial hollowing, sialocele formation, division of the greater auricular nerve and Frey's syndrome. ${ }^{10-12}$

Also known as 'local dissection', ECD was established by Gleave et al. ${ }^{11}$ This technique involves intraoperative management of the facial nerve, en bloc tumour resection and preservation of the parotid capsule and is performed in a bloodless field. ${ }^{12}$ The technique has since been advocated by McGurk et al. $^{14}$ When ECD is successfully performed, rates of local tumour recurrence, retromandibular hollowing and facial nerve injury are reduced. ${ }^{12} 13$ It should be noted, however, that, if performed incorrectly, ECD may relapse into enucleation of the tumour which should be avoided. ${ }^{12} 13$

It is possible to differentiate between malignant and benign neoplasia through clinical examination in $93-96 \%$ of cases when the initial skin flap over the parotid is reflected. ${ }^{12}$ Fixation of the neoplasm to deeper or adjacent structures is indicative of a malignant tumour and should guide the surgeon in converting an ECD to a formal superficial parotidectomy. Should a small ambiguous lump be encountered, surgical caution is advised, with reasonable excision margins suggested in case of malignant cell type. Often, if a suitable margin is taken around a suspicious small neoplasm, no further surgical treatment is required. ${ }^{13-15}$

Notably, FNAc of the parotid has been shown to provide low sensitivity when differentiating between benign and malignant disease of the parotid, ${ }^{16}$ and therefore malignant disease cannot be ruled out. In the UK the sensitivity of FNAc in differentiating between malignant and benign parotid disease was reported as $38 \%(95 \%$ CI $13 \%$ to $63 \%$ ) in a district general hospital and $79 \%$ (95\% CI $61 \%$ to $97 \%$ ) in a university teaching hospital. ${ }^{16}$ There is ongoing discussion in the head and neck community regarding the utility of FNAc in parotid tumours, with many groups now suggesting that other diagnostic techniques such as therapeutic ECD and mini Trucut biopsy (ultrasound-guided small gauge core needle biopsy) are superior. ${ }^{17-19}$ Mini Trucut 
biopsy uses a needle tip of the same diameter as that used for FNAc (14-18 gauge). ${ }^{18} 19$ In our case, the diagnosis of benign pathology was made clinically before surgical intervention, with postoperative tissue typing confirming the cytoarchitectural features of myopericytoma.

A recent published series of 176 ECDs was compared with a series of 56 superficial parotidectomies in Naples, Italy. ${ }^{20}$ The authors reported fewer postoperative complications (facial nerve injury, transient facial paralysis and Frey's syndrome) following ECD, which reached statistical significance. The authors concluded that ECD should be considered the treatment of choice for tumours arising from the superficial lobe of the parotid gland. ${ }^{20}$ Furthermore, a meta-analysis of ECD verses superficial parotidectomy in 1882 patients showed no difference in oncological recurrence of resected benign neoplasia between individuals pooled into groups according to the procedure undertaken. ${ }^{21}$ Permanent facial nerve paralysis also did not differ between groups, but Frey's syndrome and transient paresis were significantly reduced in the pooled ECD group. ${ }^{21}$ In a series of 377 patients undergoing ECD, reported complications included hypoesthesia of the cheek and earlobe (10\%), seroma (5\%), haematoma (3\%) and salivary fistula formation $(2 \%) .^{15}$ Bleeding was reported in $0.8 \%$ of cases. ${ }^{15}$ Another series of 27 patients undergoing ECD had even fewer complications with a single case of sialocele documented. ${ }^{22}$

The ECD method of excision avoids the need to extensively dissect parotid tissue adjacent to the facial nerve beyond the parts of the nerve that lie close to the tumour. ${ }^{23}$ In patients undergoing ECD the hospital stay is usually shortened to $24 \mathrm{~h}$ and the procedure can often be performed as a day case. ${ }^{23}$ ECD allows the use of a modified facelift incision which runs down the tragal crest and behind the ear and avoids division of the greater auricular nerve. This is more discrete than the traditional 'Blair' incision which runs vertically in front of the ear and curves around into the neck. ${ }^{23}$ Excision of healthy tissue is minimised, which allows re-approximation of the parotid fascia over pre-existing contours, thus maintaining a symmetrical facial appearance resulting in a superior aesthetic result compared with superficial parotidectomy. ${ }^{18}$ Spillage or rupture of the tumour, which can result in oncological seeding, may be avoided by excising the tumour with an adequate margin of healthy tissue.

ECD is minimally invasive and, given an appropriate case load to maintain this skill, provides the surgeon with an optimal approach to suspected benign superficial parotid neoplasia. It should yield clinically superior and aesthetically pleasing results compared with superficial parotidectomy, with similar oncological outcomes.

\section{Learning points}

- Myopericytoma of the parotid is an exceedingly rare benign vascular neoplasm.

- Preoperative fine needle aspiration of suspected benign parotid neoplasia is not always necessary or reliable.

- Extracapsular dissection of the parotid is minimally invasive and may be used to resect benign parotid neoplasia. The extracapsular dissection technique thus provides superior functional and aesthetic results compared with superficial parotidectomy.
Contributors ASB wrote the report and performed a literature search. PC diagnosed myopericytoma, provided secondary sources of literature and reviewed draft editions. GJK performed the surgical excision and edited the manuscript.

\section{Competing interests None.}

Patient consent Obtained.

Provenance and peer review Not commissioned; externally peer reviewed.

\section{REFERENCES}

1 Requena L, Kutzner $\mathrm{H}$, Hugel $\mathrm{H}$, et al. Cutaneous adult myofibroma: a vascular neoplasm. J Cutan Pathol 1996;23:445-57.

2 Granter SR, Badizadegan K, Fletcher CD. Myofibromatosis in adults, glomangiopericytoma and myopericytoma: a spectrum of tumours showing perivascular myoid differentiation. Am J Surg Pathol 1998;22:513-25.

3 Fletcher CDM, Unni KK, Mertens F, eds. World Health Organization classification of tumours. Pathology and genetics of tumours of soft tissue and bone. 3rd edn. Lyon: International Agency for Research on Cancer Press, 2002.

4 Mentzel T, Dei Tos AP, Sapi Z, et al. Myopericytoma of skin and soft tissues: clinicopathologic and immunohistochemical study of 54 cases. Am J Surg Pathol 2006;30:104-13

5 Tsuneyoshi M, Enjoji M. Glomus tumour: a clinicopathologic and electron microscopy study. Cancer 1982;50:1601-7.

6 Pinkston JA, Cole P. Incidence rates of salivary gland tumors: results from a population-based study. Otolaryngol Head Neck Surg 1999;120:834-40.

7 Xia L, Chen Y, Geng N, et al. Multifocal myopericytoma in the maxillofacial region: a case report. Oral Surg Oral Med Oral Pathol Oral Radiol Endod 2010;109: e59-62.

8 Jung $\mathrm{Yl}$, Chung YK, Chung S. Multiple myopericytoma of the face and parotid gland. Arch Plast Surg 2012;39:158-61.

9 Kuczkowski J, Rzepko R, Szurowska E. Myopericytoma of the parotid gland-a pathological conundrum. J Craniomaxillofac Surg 2010;38:595-6.

10 Chu ZG, Yu JQ, Yang ZG, et al. Myopericytoma involving the parotid gland as depicted on multidetector CT. Korean J Radiol 2009;10:398-401.

11 National Institute for Clinical Excellence. Improving outcomes in head and neck cancers. 2004. http://www.nice.org.uk/nicemedia/live/10897/28851/28851.pdf (accessed 29 Dec 2013).

12 Fukushima M, Miyaguchi M, Kitahara T. Extracapsular dissection: minimally invasive surgery applied to patients with parotid pleomorphic adenoma. Acta Otolaryngol 2011;131:653-9.

13 Gleave EN, Whittaker JS, Nicholson A. Salivary tumours: experience over thirty years. Clin Otolaryngol Allied Sci 1979;4:247-57.

14 McGurk M, Thomas BL, Renehan AG. Extracapsular dissection for clinically benign parotid lumps: reduced morbidity without oncological compromise. $\mathrm{Br} J$ Cancer 2003;89:1610-13.

15 Klintworth N, Zenk J, Koch M, et al. Postoperative complications after extracapsular dissection of benign parotid lesions with particular reference to facial nerve function. Laryngoscope 2010;120:484-90

16 Balakrishnan K, Castling B, McMahon J, et al. Fine needle aspiration cytology in the management of a parotid mass: a two centre retrospective study. Surgeon 2005;3:67-72.

17 Howlett DC. Diagnosing a parotid lump: fine needle aspiration cytology or core biopsy? Br J Radiol 2006;79:295-7.

18 Douville NJ, Bradford CR. Comparison of ultrasound-guided core biopsy versus fine-needle aspiration biopsy in the evaluation of salivary gland lesions. Head Neck 2012:35:1657-61.

19 Wan YL, Chan SC, Chen YL, et al. Ultrasonography-guided core-needle biopsy of parotid gland masses. AJNR Am J Neuroradiol 2004;25:1608-12.

20 Dell'Aversana Orabona G, Bonavolontà $\mathrm{P}$, laconetta $\mathrm{G}$, et al. Surgical management of benign tumors of the parotid gland: extracapsular dissection versus superficial parotidectomy_our experience in 232 cases. J Oral Maxillofac Surg 2013;71: 410-13.

21 Albergotti WG, Nguyen SA, Zenk J, et al. Extracapsular dissection for benign parotid tumors: a meta-analysis. Laryngoscope 2012;122:1954-60.

22 Smith SL, Komisar A. Limited parotidectomy: the role of extracapsular dissection in parotid gland neoplasms. Laryngoscope 2007;117:1163-7.

23 George KS, McGurk M. Extracapsular dissection-minimal resection for benign parotid tumours. Br J Oral Maxillofac Surg 2011;49:451-4 
Copyright 2014 BMJ Publishing Group. All rights reserved. For permission to reuse any of this content visit http://group.bmj.com/group/rights-licensing/permissions.

BMJ Case Report Fellows may re-use this article for personal use and teaching without any further permission.

Become a Fellow of BMJ Case Reports today and you can:

- Submit as many cases as you like

- Enjoy fast sympathetic peer review and rapid publication of accepted articles

- Access all the published articles

- Re-use any of the published material for personal use and teaching without further permission

For information on Institutional Fellowships contact consortiasales@bmjgroup.com

Visit casereports.bmj.com for more articles like this and to become a Fellow 